\title{
Organic and inorganic amendments on soil chemical properties at different period of incubation of acidic soil
}

\section{Endalkachew Fekadu a,*, Kibebew Kibret a, Bobe Bedadi a Asmare Melese b, Birru Yitaferu c}

a School of Natural Resources Management and Environmental Sciences, Haramaya University, Dire Dawa, Ethiopia

b Department of Plant Science, Debre Berhan University, Debre Berhan, Ethiopia

${ }^{c}$ Amhara Regional Agricultural Research Institute, Bahir Dar, Ethiopia

\section{Article Info}

Received : 08.08.2017

Accepted : 09.06.2018

\begin{abstract}
Soil acidity is a critical issue necessitating urgent attention in most highlands of Ethiopia due to its impact on crop production productivity. Application of organic and inorganic amendments could effectively minimize the problem and improve the fertility level of the soil. Accordingly, a greenhouse experiment was conducted to evaluate the effects of sole and combined applications of lime, FYM, compost and P on soil chemical properties incubated at 20, 40 and 60 days. The treatments were arranged in a completely randomized design with three replications. The results indicated that various treatment combinations raised the soil $\mathrm{pH}$ at the 40 days of incubation. All treatments showed increased $\mathrm{P}$ availability consistently with increasing time of incubation. Maximum available $\mathrm{P}$ was observed at the 60 days of incubation due to application of $8 \mathrm{t} \mathrm{FYM} \mathrm{ha-1+}$ $30 \mathrm{~kg} \mathrm{P} \mathrm{ha}^{-1}+5 \mathrm{t}$ lime ha-1 followed by $8 \mathrm{t}$ compost ha ${ }^{-1}+30 \mathrm{~kg} \mathrm{P} \mathrm{ha}^{-1}+5 \mathrm{t} \mathrm{lime} \mathrm{ha-1}$. Exchangeable acidity and $\mathrm{Al}$ were reduced at the 40 and 60 days of incubation with the

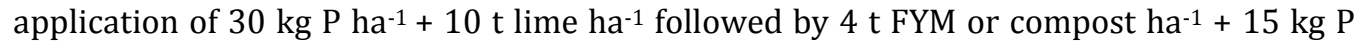
$\mathrm{ha}^{-1}+10 \mathrm{t}$ lime ha-1. Highest exchangeable Ca was obtained at 20 days of incubation with

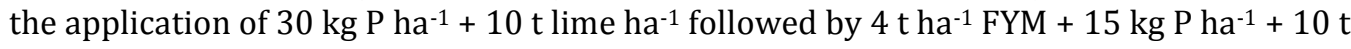
lime ha-1. Sole addition of $10 \mathrm{t}$ lime ha-1 elevated ECEC from 19.29 to $22.30 \mathrm{cmol}_{\mathrm{c}} \mathrm{kg}^{-1}$ at the 40 days of incubation. Likewise, combined applications of $30 \mathrm{~kg} \mathrm{P} \mathrm{ha}^{-1}+10 \mathrm{tlime} \mathrm{ha}^{-1}$ improved ECEC of the soil from 19.53 to $24.27 \mathrm{cmol}_{\mathrm{c}} \mathrm{kg}^{-1}$ at the 40 days of incubation. Integrated applications of organic and inorganic amendments were found more effective to reduce soil acidity and $\mathrm{Al}^{3+}$ concentration with increasing the fertility of the soil.
\end{abstract}

Keywords: Farmyard manure, compost, soil acidity, incubation.

(C) 2018 Federation of Eurasian Soil Science Societies. All rights reserved

\section{Introduction}

Soil acidity is a critical issue requiring urgent attention in most highlands of Ethiopia due to its impact on crop production and productivity (Tessema et al., 2012). Recent studies have also indicated that soil acidity affects large areas of the cultivated lands in different parts of Ethiopia (Wassie and Shiferaw, 2009; Melese and Yli-Halla, 2016).

Most acidic soils have been found to be low in fertility, have poor chemical and biological properties. Strong soil acidity is associated with $\mathrm{Al}, \mathrm{H}, \mathrm{Fe}, \mathrm{Mn}$ toxicities to plant roots in the soil solutions and corresponding deficiencies of the available P, Mo, Ca, Mg and K (Kisinyo et al., 2014). Aluminum toxicity primary affects the root apex and causes stunting of the primary root and inhibition of lateral root formation.

Several practices have been recommended to reclaim acidity and upgrade the productivity of strongly acidic soils. These include the cultivation of acid tolerant plants, covering the surface with non-acidic soil, the use

\footnotetext{
${ }^{*}$ Corresponding author.

School of Natural Resources Management and Environmental Sciences, Haramaya University, P.O. Box 138, Dire Dawa, Ethiopia

Tel.: +251935723891

E-mail address: endalkf@gmail.com

e-ISSN: 2147-4249 DOI: $10.18393 /$ ejss.435095
} 
of organic fertilizers, and liming. Of these practices, liming and the application of organic fertilizers are generally considered to be the best measures, because their effects are more persistent (Chen et al., 2001). However, the unaffordability of fertilizers and lime, and unsustainable crop production calls for use of locally available low cost organic sources through manures, green manures, and mineral fertilizers in a harmonized combination for sustainable production and soil quality. Lime in the form of calcium carbonate or dolomite is applied to acid soils to increase the $\mathrm{pH}, \mathrm{Ca}$ concentration, $\mathrm{CEC}$ and base saturation, and to eliminate $\mathrm{Al}$ and Mn toxicity and P fixation (Fageria and Baligar, 2003; Ano and Ubochi, 2007). Another research indicated liming can increase, decrease, or have no effect on P availability (Anjos and Rowell, 1987). However, the recent studies (Crawford et al., 2008; Osundwa et al., 2013; Melese and Yli-Hall, 2016) indicated a significant increase in Olsen $\mathrm{P}$ due to liming acidic soils.

Addition of manure and compost to acidic soils is potentially a feasible approach for increasing soil $\mathrm{pH}$, decreasing concentrations of Al, reducing lime requirements (Mokolobate and Haynes, 2002; Crawford et al., 2008; Opala et al., 2012). Application of OM like compost and manures provide nutrients and improve the physical properties the soil (Chiu et al., 2006). The role of composts as a complimentary amendment for improving the soil aggregation, increasing the microbial biomass, improving the moisture holding capacity, raising the CEC and pH of the soil has been recognized by various researchers (Valarini et al., 2009; Martínez-Blanco et al., 2013).

Although all these mentioned organic and inorganic amendments have significant contribution to reduce soil acidity and improve soil fertility and nutrient transfer, farming in the highlands of Ethiopia is characterized by low agricultural productivity as compared with developed countries due to progressive soil fertility decline over the years, and inadequate applications of amendments. The amount and the time of separate or combined applications of lime, manure, compost and inorganic fertilizers applied to the soil and the chemical effects observed are not sufficiently investigated in various areas of Ethiopia.

Improved soil fertility, and acidity management through the use of combining organic and inorganic amendments enable efficient use of the inputs applied and increase agricultural productivity. However, manure or compost is used mostly on small plots that are located around the household's residence, and the quantity of amendments and the time of application is not research based to ameliorate the soil and meet the need of crops. Hence, this study was proposed with the objective of determining the effects of lime, mineral $\mathrm{P}$, FYM and compost on selected soil chemical properties at different period of incubation of cultivated acidic soils at Lay Gayint district.

\section{Material and Methods}

\section{Description of the study area}

The study was conducted at Lay Gayint district of South Gondar Zone of the Amhara National Regional State (ANRS), Ethiopia. Lay Gayint district is located at about $175 \mathrm{~km}$ northeast of Bahir Dar, along the WoretaWoldia highway (Figure 1). The district lies between the coordinates of $11^{\circ} 32^{\prime}-12^{\circ} 16^{\prime} \mathrm{N}$ and $38^{\circ} 12^{\prime}-38^{\circ} 19^{\prime} \mathrm{E}$, and covers an estimated area of $1511 \mathrm{~km}^{2}$. Altitude of Lay Gayint district varies between 1500 and 4235 meters above sea level (masl). Physiographically, the area is characterized by plain $(10 \%)$, undulating $(70 \%)$, mountainous $(15 \%)$ and gorges and valleys $(5 \%)$. The major land use patterns of the study area comprise of cultivated land (44\%), grazing land (14\%), forest/bush land (5\%), water body (2\%) infrastructure and settlement (6\%), and unproductive land (29\%). Agro-ecologically, the district is divided into four elevation and temperature zones, namely: lowland (kolla) (12.5\%), midland (woina-dega) (39.42\%), highland (dega) (45.39\%), and wurch (very cold or alpine) (2.71\%) (Addisu and Menberu, 2015). Lay Gayint district receives a mean annual rainfall of $1020 \mathrm{~mm}$. The main rainy season, which represents the long rainy season (meher), occurs between June and September, and the small rainy season (belg) occurs between March and May. The mean minimum and maximum air temperature of the district are 6.9 and 21.9 ${ }^{0} \mathrm{C}$, respectively (ENMSA, 2017).

\section{Soil sampling and sample preparation}

Surface soil samples of cultivated lands at Lay Gayint district, with pH less than 5.5 was measured at field condition using portable $\mathrm{pH}$ meter, were collected in bulk using auger and spade at 0 to $20 \mathrm{~cm}$ soil depth. The collected soil samples were bulked to make a composite sample. The soil samples were air dried, crushed and made to pass through a $2 \mathrm{~mm}$ sieve size for the analysis of soil $\mathrm{pH}$, texture, available $\mathrm{P}$, exchangeable bases, exchangeable acidity and $\mathrm{Al}$, and CEC. For analysis of OC and total $\mathrm{N}$, samples were made to pass through $0.5 \mathrm{~mm}$ sieve size. The composite soil samples were analyzed based on standard laboratory procedures. 


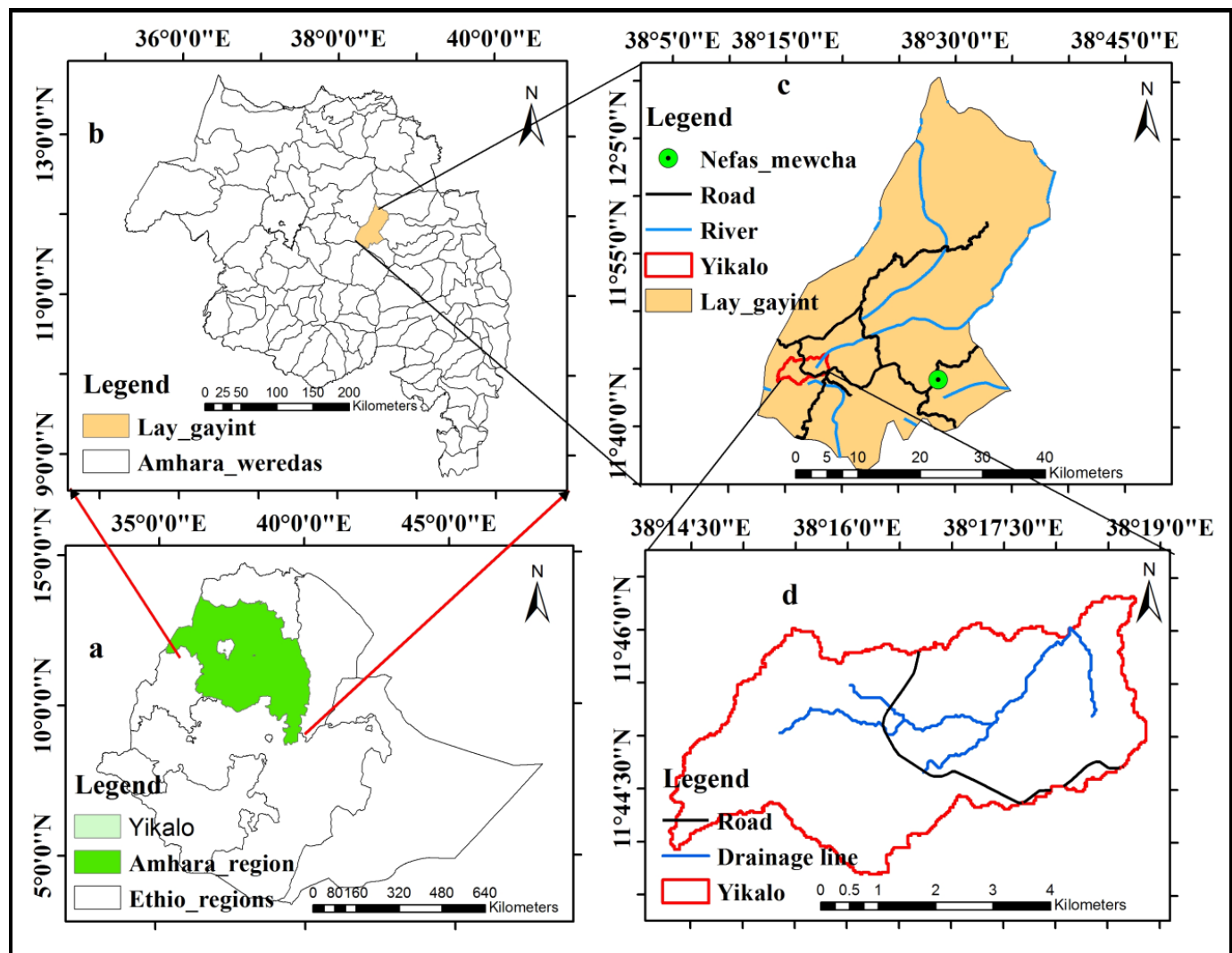

Figure 1. Location map of the study area: (a) ANRS in Ethiopia (b) Lay Gayint district in ANRS (c) Study area (d) Drainage lines.

Soil texture was determined using Bouyoucos hydrometer method (Day, 1965). Bulk density (BD) was determined from undisturbed (core) soil samples collected using core samplers, weighed at field moisture content and then dried in an oven at $105^{\circ} \mathrm{C}$ (Baruah and Barthakur, 1997). The $\mathrm{pH}$ of the soil was measured potentiometrically in the supernatant suspension of a 1:2.5 soil to water ratio using a $\mathrm{pH}$ meter. Organic carbon was determined using the wet oxidation method (Walkley and Black, 1934) where the carbon was oxidized under standard conditions with potassium dichromate $\left(\mathrm{K}_{2} \mathrm{Cr}_{2} \mathrm{O}_{7}\right)$ in sulfuric acid $\left(\mathrm{H}_{2} \mathrm{SO}_{4}\right)$ solution. Total $\mathrm{N}$ was determined by the Kjeldahl method (Jackson, 1967) while available $\mathrm{P}$ was extracted using the sodium bicarbonate solution following the procedure described by Olsen et al. (1954). The exchangeable cations ( $\mathrm{Ca}, \mathrm{Mg}, \mathrm{K}$ and $\mathrm{Na}$ ) were extracted with $1 \mathrm{M}$ ammonium acetate $\left(\mathrm{NH}_{4} \mathrm{OAc}\right.$ ) solution at $\mathrm{pH} 7.0$ (Jackson, 1967). Exchangeable $\mathrm{Ca}$ and $\mathrm{Mg}$ in the leachate were determined by atomic absorption spectrophotometer (AAS), while exchangeable $\mathrm{K}$ and $\mathrm{Na}$ were determined by flame photometry (Rowell, 1994). Lime requirement (LR) of the soil was determined by Shoemaker, McLean and Pratt (SMP) single buffer procedure (Shoemaker et al., 1961). The potential cation exchange capacity (CEC) of the soil was determined from the $\mathrm{NH}_{4}{ }^{+}$saturated samples that were subsequently replaced by $\mathrm{K}^{+}$using $\mathrm{KCl}$ solution. The excess salt was removed by washing with ethanol and the $\mathrm{NH}_{4}{ }^{+}$that was displaced by $\mathrm{K}^{+}$was measured using the microKjeldahl procedure (Chapman, 1965) and reported as CEC. Total exchangeable acidity was determined by saturating the soil samples with $1 \mathrm{M} \mathrm{KCl}$ solution and was titrated with $0.02 \mathrm{M} \mathrm{NaOH}$ as described by Rowell (1994). From the same extract, exchangeable $\mathrm{Al}$ in the soil samples was determined by application of $1 \mathrm{M}$ $\mathrm{NaF}$ which formed a complex with $\mathrm{Al}$ and released $\mathrm{NaOH}$ and then $\mathrm{NaOH}$ was back titrated with a standard solution of $0.02 \mathrm{M} \mathrm{HCl}$. The analytical soil data is indicated in Table 1.

Manure and compost $\mathrm{pH}$ was measured in water (soil: solution ratio of 1:5) using a pH meter with a glass and reference calomel electrode after the suspensions was shaken for 30 minutes and allowed to stand for 1 hour (John, 2003). Total N content was determined by Kjedahl method as described by Jackson (1967). The organic carbon was determined by wet oxidation method through chromic acid digestion (Walkley and Black, 1934). Total $\mathrm{P}, \mathrm{K}, \mathrm{Ca}, \mathrm{Mg}$ and Fe were determined following wet digestion with $\mathrm{H}_{2} \mathrm{O}_{2} / \mathrm{H}_{2} \mathrm{SO}_{4}$ (Okalebo et al., 2002). Total $\mathrm{Ca}, \mathrm{Mg}$, $\mathrm{K}$ and Na were determined by AAS and $\mathrm{P}$ measured as described by Murphy and Riley (1962). The neutralization value of the Dejen lime was determined by dissolving a graduated amount of lime with excess of standard $0.5 \mathrm{M} \mathrm{HCl}$ (Table 2). The excess acid was back titrated with standard $0.1 \mathrm{M}$ $\mathrm{NaOH}$ solution using phenolphthalein as an indicator after filtration. From the amount of $\mathrm{NaOH}$ used to neutralize the excess acid of the blank and the filtrate, the neutralization value of the lime was calculated. 
Table 1. Selected physical and chemical properties of the experimental soil

\begin{tabular}{lr}
\hline Parameter & Value \\
\hline Sand (\%) & 19 \\
Silt (\%) & 36 \\
Clay (\%) & 45 \\
Textural class & clay \\
Bulk density $\left(\mathrm{g} \mathrm{cm}^{-3}\right)$ & 1.4 \\
$\mathrm{pH}\left(\mathrm{H}_{2} \mathrm{O}\right)$ & 4.93 \\
Exchangeable $\mathrm{Ca}\left(\mathrm{cmol}_{\mathrm{c}} \mathrm{kg}^{-1}\right)$ & 9.98 \\
Exchangeable $\mathrm{Mg}\left(\mathrm{cmol}_{\mathrm{c}} \mathrm{kg}^{-1}\right)$ & 4.26 \\
Exchangeable $\mathrm{K}\left(\mathrm{cmol}_{\mathrm{c}} \mathrm{kg}^{-1}\right)$ & 0.45 \\
Exchangeable $\mathrm{Na}\left(\mathrm{cmol}_{\mathrm{c}} \mathrm{kg}^{-1}\right)$ & 0.38 \\
Cation exchange capacity $\left(\mathrm{cmol}_{\mathrm{c}} \mathrm{kg}^{-1}\right)$ & 33.7 \\
Exchangeable $\mathrm{acidity}\left(\mathrm{cmol}_{\mathrm{c}} \mathrm{kg}^{-1}\right)$ & 4.04 \\
Exchangeable $\mathrm{Al}\left(\mathrm{cmol}_{\mathrm{c}} \mathrm{kg}^{-1}\right)$ & 1.77 \\
Organic carbon $(\%)$ & 1.27 \\
Total nitrogen $(\%)$ & 0.19 \\
Olsen P $(\mathrm{mg} \mathrm{kg})$ & 5.87 \\
\hline
\end{tabular}

Table 2. Chemical characteristics of FYM and compost

\begin{tabular}{|c|c|c|c|c|c|c|c|c|}
\hline \multirow[t]{2}{*}{ Amendment } & \multirow{2}{*}{$\begin{array}{c}\mathrm{pH}-\mathrm{H}_{2} \mathrm{O} \\
(1: 5)\end{array}$} & $\mathrm{N}$ & $\mathrm{C}$ & $\mathrm{P}$ & $\mathrm{Ca}$ & K & $\mathrm{Mg}$ & $\mathrm{Na}$ \\
\hline & & \multicolumn{7}{|c|}{ 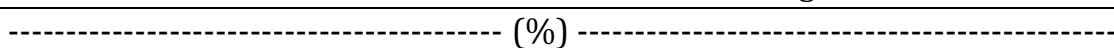 } \\
\hline Farmyard manure & 7.6 & 1.11 & 13.87 & 0.31 & 1.52 & 1.51 & 0.72 & 0.14 \\
\hline Compost & 7.2 & 0.51 & 18.40 & 0.29 & 1.43 & 1.63 & 0.59 & 0.15 \\
\hline
\end{tabular}

\section{Incubation study}

Based on the $\mathrm{pH}$ and the LR, composite soil samples of the acidic soil were selected for this experiment. The composite soil samples were air dried ground and passed with $2 \mathrm{~mm}$ sieve and then placed separately in plastic containers and mixed with different treatments in a laboratory. The treatments were lime, mineral $\mathrm{P}$ fertilizer, FYM and compost which were applied separately and in systematic combination at different rates (Table 1). Manure and compost, dried and ground to pass through a $0.25 \mathrm{~mm}$ sieve, were added. Lime with a known mesh size was added based on the LR of the soil. The lime used for the experiments was found to have a neutralization value of $93.8 \%$. A completely randomized design (CRD) was used and treatments were replicated three times. The study was conducted in plastic containers with $500 \mathrm{~g}$ of soil in each plastic container. Lime, mineral $P$ fertilizer, manure and compost were incubated for two months in the greenhouse. All pots were subjected to wetting and drying cycles during the incubation period. Soil samples were drawn at 20, 40 and 60 days of the incubation period and then were air dried, ground and sieved through a $2 \mathrm{~mm}$ sieve and used for analysis of soil $\mathrm{pH}$, exchangeable acidity, exchangeable $\mathrm{Al}$, exchangeable bases, ECEC and available P.

\section{Statistical analysis}

The data obtained was subjected to analysis of variance (ANOVA) following procedures that are appropriate to experimental design with the help of statistical analysis system (SAS) software package version 9.1. Duncan's Multiple Range Test (DMRT) was employed to test the significance difference between means of treatments.

\section{Results and Discussion}

\section{Effects of organic and inorganic amendments on soil $\mathrm{pH}$ and available $\mathrm{P}$}

Soil pH was significantly $(\mathrm{P}<0.001)$ increased with single or combined applications of treatments except sole P. Soil pH improvement was observed at the 20 days of incubation and continued rise to the 40 days and declined to the 60 days for some of the treatments (Table 4). Application of $30 \mathrm{~kg} \mathrm{P} \mathrm{ha}^{-1}+10 \mathrm{tlime} \mathrm{ha}^{-1}$

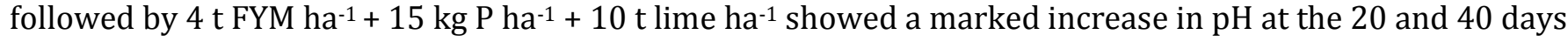
of incubation and a decrease at 60 days of incubation. Regarding to separately applied treatments, the effect of lime to reduce the level of soil acidity was observed more immediate as depicted in Table 4.

Application of organic and inorganic amendments significantly improved available $P$ at various period of incubation over the control. All treatments showed increased P availability consistently with increasing time of incubation. Maximum available $P$ was observed at the 60 days of incubation due to application of $8 \mathrm{t}$ FYM $\mathrm{ha}^{-1}+30 \mathrm{~kg} \mathrm{P} \mathrm{ha}^{-1}+5 \mathrm{t}$ lime ha-1 followed by $8 \mathrm{t}$ compost ha-1 $+30 \mathrm{~kg} \mathrm{P} \mathrm{ha}^{-1}+5 \mathrm{t} \mathrm{lime} \mathrm{ha-1}$. On the other hand, more available $\mathrm{P}$ was obtained at the 20 days of incubation with combination of $30 \mathrm{~kg} \mathrm{P}^{\mathrm{P}} \mathrm{a}^{-1}$ with $10 \mathrm{t}$ lime 
$\mathrm{ha}^{-1}$. Separate addition of $30 \mathrm{~kg} \mathrm{P} \mathrm{ha}^{-1}$ and $8 \mathrm{t} \mathrm{FYM} \mathrm{ha}^{-1}$ resulted in increased available $\mathrm{P}$ by 52 and $48 \%$, respectively over the control at the 60 days of incubation. Combined applications of $8 \mathrm{t} \mathrm{FYM} \mathrm{ha-1,30} \mathrm{kg} \mathrm{P} \mathrm{ha-1}$ with $5 \mathrm{t}$ lime ha-1 added significantly more available $\mathrm{P}$ with an increase of $70 \%$, over the control at the 60 days of incubation.

Table 4. Effects of organic and inorganic amendments on soil $\mathrm{pH}$ and available $\mathrm{P}$

\begin{tabular}{|c|c|c|c|c|c|c|}
\hline \multirow[t]{2}{*}{ Treatments } & 20 days & 40 days & 60 days & 20 days & 40 days & 60 days \\
\hline & \multicolumn{3}{|c|}{ Soil pH } & \multicolumn{3}{|c|}{ Available P (mg kg-1) } \\
\hline Control & $4.85 \mathrm{~m}$ & $4.87 \mathrm{~lm}$ & $4.951 \mathrm{~lm}$ & $5.87 q$ & $6.271-q$ & $6.76 f-1$ \\
\hline 8 t compost ha ${ }^{-1}$ & $5.21 \mathrm{~lm}$ & $5.21 \mathrm{klm}$ & 5.361 & $6.60 n-q$ & $6.79 m-q$ & $9.27 \mathrm{~b}-\mathrm{h}$ \\
\hline 8 t FYM ha-1 & $5.19 \mathrm{~lm}$ & $5.29 \mathrm{klm}$ & $5.35 \mathrm{klm}$ & $6.22 \mathrm{pq}$ & $6.54 o p q$ & $10.01 \mathrm{a}-\mathrm{g}$ \\
\hline $30 \mathrm{~kg} \mathrm{P} \mathrm{ha}^{-1}$ & $4.99 \mathrm{~lm}$ & $4.891 \mathrm{~lm}$ & $4.89 \mathrm{klm}$ & 8.33 e-n & $9.19 \mathrm{~b}-\mathrm{k}$ & $10.28 a-d$ \\
\hline $10 \mathrm{t} \mathrm{lime} \mathrm{ha}^{-1}$ & $5.99 \mathrm{~d}-\mathrm{h}$ & $6.22 b-e$ & $6.11 \mathrm{c}-\mathrm{g}$ & $6.19 \mathrm{pq}$ & $7.61 \mathrm{i}-\mathrm{q}$ & $9.27 \mathrm{~b}-\mathrm{k}$ \\
\hline $30 \mathrm{~kg} \mathrm{P} \mathrm{ha}^{-1}+10 \mathrm{t} \mathrm{lime} \mathrm{ha}^{-1}$ & $6.26 \mathrm{bcd}$ & $6.59 \mathrm{a}$ & $6.10 \mathrm{c}-\mathrm{g}$ & $10.33 \mathrm{a}-\mathrm{d}$ & $9.40 \mathrm{~b}-\mathrm{k}$ & $10.87 a-d$ \\
\hline $30 \mathrm{~kg} \mathrm{P} \mathrm{ha}^{-1}+5$ t lime ha-1 & 5.76ghi & $6.12 c-f$ & $5.93 e-i$ & $6.82 \mathrm{l}-\mathrm{q}$ & $7.92 \mathrm{~g}-\mathrm{q}$ & $10.12 a-f$ \\
\hline 8 t compost ha-1 +5 t lime ha ${ }^{-1}$ & $5.87 g-j$ & $5.91 \mathrm{f}-\mathrm{i}$ & $5.56 \mathrm{jk}$ & $7.46 \mathrm{j}-\mathrm{q}$ & $7.69 \mathrm{i}-\mathrm{q}$ & $9.35 b-k$ \\
\hline 8 t FYM ha $^{-1}+5$ t lime ha-1 & $5.91 \mathrm{e}-\mathrm{i}$ & $6.11 \mathrm{c}-\mathrm{g}$ & $5.89 \mathrm{f}-\mathrm{i}$ & $6.82 \mathrm{l}-\mathrm{q}$ & $7.29 \mathrm{k}-\mathrm{q}$ & $9.21 \mathrm{~b}-\mathrm{k}$ \\
\hline 8 t compost ha ${ }^{-1}+30 \mathrm{~kg} \mathrm{Pha}^{-1}+5 \mathrm{t}^{\mathrm{time} \mathrm{ha}} \mathrm{h}^{-1}$ & $5.94 \mathrm{e}-\mathrm{i}$ & $5.95 \mathrm{~d}-\mathrm{i}$ & $5.87 \mathrm{~g}-\mathrm{j}$ & $7.91 \mathrm{e}-1$ & $8.05 \mathrm{f}-\mathrm{o}$ & $11.10 \mathrm{ab}$ \\
\hline 8 t FYM ha-1 $+30 \mathrm{~kg} \mathrm{P} \mathrm{ha}^{-1}+5$ t lime ha $^{-1}$ & $5.91 \mathrm{f}-\mathrm{i}$ & $5.94 \mathrm{e}-\mathrm{i}$ & 5.79ghi & $9.45 \mathrm{a}-\mathrm{j}$ & $10.05 a-f$ & $11.52 \mathrm{a}$ \\
\hline 4 t compost ha-1 $+15 \mathrm{~kg} \mathrm{Pha}^{-1}+10 \mathrm{t} \mathrm{lime} \mathrm{ha}^{-1}$ & $6.03 c-h$ & $6.32 \mathrm{abc}$ & $6.03 c-h$ & $9.69 a-i$ & $9.84 a-h$ & $10.43 a-d$ \\
\hline 4 t FYM ha-1 $+15 \mathrm{~kg} \mathrm{P} \mathrm{ha}^{-1}+10 \mathrm{t} \mathrm{lime} \mathrm{ha}^{-1}$ & $6.43 \mathrm{ab}$ & $6.48 \mathrm{ab}$ & $6.19 b-f$ & $8.81 \mathrm{~d}-\mathrm{m}$ & 8.91c-l & $10.93 \mathrm{abc}$ \\
\hline 4 t compost ha ${ }^{-1}+15 \mathrm{~kg} \mathrm{Pha}^{-1}+5 \mathrm{t} \mathrm{lime} \mathrm{ha}^{-1}$ & $5.56 \mathrm{jk}$ & $5.91 \mathrm{f}-\mathrm{i}$ & $5.86 \mathrm{~g}-\mathrm{j}$ & $6.72 m-q$ & $7.82 \mathrm{~h}-\mathrm{q}$ & $8.80 \mathrm{~d}-\mathrm{m}$ \\
\hline 4 t FYM ha-1 $+15 \mathrm{~kg} \mathrm{Pha}^{-1}+5 \mathrm{t} \mathrm{lime} \mathrm{ha}^{-1}$ & $5.67 \mathrm{ij}$ & $5.97 \mathrm{~d}-\mathrm{i}$ & $5.75 \mathrm{ghi}$ & $6.811-\mathrm{q}$ & $8.66 \mathrm{e}-\mathrm{n}$ & 9.99a-g \\
\hline CV (\%) & \multicolumn{3}{|c|}{3.32} & \multicolumn{3}{|c|}{11.75} \\
\hline
\end{tabular}

Means within a column followed by the same letter are not significantly different at $\mathrm{P}>0.001 ; \mathrm{CV}=$ coefficient of variation

\section{Effects of organic and inorganic amendments on exchangeable acidity and Al}

Exchangeable acidity and $\mathrm{Al}$ were affected significantly due to application of treatments and over incubation period. Maximum reduction of exchangeable acidity and $\mathrm{Al}$ were recorded with the application of $30 \mathrm{~kg} \mathrm{P}$ ha$1+10$ t lime ha-1 followed by $4 \mathrm{t} \mathrm{FYM}$ or compost ha-1 $+15 \mathrm{~kg} \mathrm{P}^{-1}+10 \mathrm{t}$ lime ha-1.

Table 5. Effects of organic and inorganic amendments on exchangeable acidity and Al

\begin{tabular}{|c|c|c|c|c|c|c|}
\hline \multirow[t]{2}{*}{ Treatments } & 20 days & 40 days & 60 days & 20 days & 40 days & 60 days \\
\hline & \multicolumn{3}{|c|}{ Ex acidity $\left(\mathrm{cmol}_{\mathrm{c}} \mathrm{kg}^{-1}\right)$} & \multicolumn{3}{|c|}{$\operatorname{Ex~Al}\left(\mathrm{cmol}_{\mathrm{c}} \mathrm{kg}^{-1}\right)$} \\
\hline Control & $4.16 \mathrm{a}$ & $4.07 a$ & $3.95 \mathrm{ab}$ & $1.78 \mathrm{a}$ & $1.77 \mathrm{a}$ & $1.74 \mathrm{a}$ \\
\hline $8 \mathrm{t} \mathrm{compost} \mathrm{ha}^{-1}$ & $3.72 b$ & 2.78de & $1.31 \mathrm{ij}$ & $1.57 \mathrm{~b}$ & $1.23 c$ & $0.64 \mathrm{f}$ \\
\hline 8 t FYM ha-1 & $3.27 c$ & $2.53 \mathrm{e}$ & $1.26 \mathrm{ij}$ & $1.26 \mathrm{c}$ & $0.82 \mathrm{e}$ & $0.58 \mathrm{f}$ \\
\hline $30 \mathrm{~kg} \mathrm{P} \mathrm{ha}^{-1}$ & $4.12 \mathrm{a}$ & $4.04 \mathrm{a}$ & $3.95 \mathrm{ab}$ & $1.76 \mathrm{a}$ & $1.74 \mathrm{a}$ & $1.73 \mathrm{a}$ \\
\hline $10 \mathrm{t}^{\text {lime ha }}{ }^{-1}$ & $0.66 \mathrm{lmn}$ & $0.26 o p q$ & $0.07 q$ & $0.16 \mathrm{j}-\mathrm{m}$ & $0.03 \mathrm{mn}$ & $0.00 \mathrm{~m}$ \\
\hline $30 \mathrm{~kg} \mathrm{P} \mathrm{ha}^{-1}+10 \mathrm{t} \mathrm{lime} \mathrm{ha}^{-1}$ & $0.631 \mathrm{lmn}$ & $0.38 n-q$ & 0.040 & $0.17 \mathrm{i}-\mathrm{l}$ & $0.05 \mathrm{klm}$ & $0.00 \mathrm{~m}$ \\
\hline $30 \mathrm{~kg} \mathrm{P} \mathrm{ha}^{-1}+5 \mathrm{t}$ lime ha-1 & $2.95 \mathrm{~d}$ & $1.86 \mathrm{fg}$ & 0.53l-p & $0.99 \mathrm{~d}$ & $0.65 f$ & $0.39 \mathrm{~g}$ \\
\hline $8 \mathrm{t}$ compost ha ${ }^{-1}+5 \mathrm{t}$ lime ha $\mathrm{h}^{-1}$ & $2.76 \mathrm{de}$ & $1.52 \mathrm{hi}$ & $1.20 \mathrm{ijk}$ & $1.15 \mathrm{c}$ & $0.35 \mathrm{gh}$ & $0.15 \mathrm{j}-\mathrm{m}$ \\
\hline 8 t FYM ha-1 + 5 t lime ha ${ }^{-1}$ & $2.15 \mathrm{f}$ & $1.29 \mathrm{ij}$ & $0.551-0$ & $0.81 \mathrm{e}$ & $0.35 \mathrm{gh}$ & $0.00 \mathrm{~m}$ \\
\hline 8 t compost ha-1 $+30 \mathrm{~kg} \mathrm{P} \mathrm{ha}^{-1}+5 \mathrm{t} \mathrm{lime} \mathrm{ha}^{-1}$ & $1.81 \mathrm{gh}$ & $1.19 \mathrm{ijk}$ & $0.80 \mathrm{klm}$ & $0.63 \mathrm{f}$ & $0.31 \mathrm{ghi}$ & $0.16 \mathrm{j}-\mathrm{m}$ \\
\hline 8 t FYM ha-1 $+30 \mathrm{~kg} \mathrm{P} \mathrm{ha}^{-1}+5$ t lime ha-1 $^{-1}$ & $1.08 \mathrm{jkl}$ & $0.65 \mathrm{lmn}$ & $0.21 \mathrm{pq}$ & $0.43 \mathrm{~g}$ & $0.11 \mathrm{lmn}$ & $0.00 \mathrm{~m}$ \\
\hline $4 \mathrm{t}$ compost ha ${ }^{-1}+15 \mathrm{~kg} \mathrm{P} \mathrm{ha}^{-1}+10 \mathrm{t} \mathrm{lime} \mathrm{ha}^{-1}$ & $0.75 \mathrm{klm}$ & $0.15 q$ & $0.09 q$ & $0.23 \mathrm{hij}$ & $0.03 \mathrm{~lm}$ & $0.00 \mathrm{~m}$ \\
\hline 4 t FYM ha-1 $+15 \mathrm{~kg} \mathrm{P} \mathrm{ha}^{-1}+10 \mathrm{t}^{\mathrm{ame}} \mathrm{ha}^{-1}$ & $0.50 \mathrm{~m}-\mathrm{p}$ & $0.11 \mathrm{q}$ & $0.08 \mathrm{q}$ & $0.14 \mathrm{j}-\mathrm{m}$ & $0.00 \mathrm{~m}$ & $0.00 \mathrm{~m}$ \\
\hline 4 t compost ha-1 $+15 \mathrm{~kg} \mathrm{P} \mathrm{ha}^{-1}+5 \mathrm{t} \mathrm{lime} \mathrm{ha}^{-1}$ & $1.31 \mathrm{ij}$ & $0.88 \mathrm{klm}$ & $0.26 \mathrm{opq}$ & $0.22 \mathrm{jkl}$ & $0.05 \mathrm{klm}$ & $0.00 \mathrm{~m}$ \\
\hline 4 t FYM ha-1 $+15 \mathrm{~kg} \mathrm{P} \mathrm{ha}^{-1}+5 \mathrm{t} \mathrm{lime} \mathrm{ha}^{-1}$ & $1.24 \mathrm{ij}$ & $0.76 \mathrm{klm}$ & $0.13 q$ & $0.16 \mathrm{j}-\mathrm{m}$ & $0.03 \mathrm{~lm}$ & $0.00 \mathrm{~m}$ \\
\hline $\mathrm{CV}(\%)$ & \multicolumn{3}{|c|}{11.34} & \multicolumn{3}{|c|}{14.59} \\
\hline
\end{tabular}

Means within a column followed by the same letter are not significantly different at $\mathrm{P}>0.001$; $\mathrm{CV}=$ coefficient of variation

Statistically, application of $4 \mathrm{t} \mathrm{FYM} \mathrm{ha-1}+15 \mathrm{~kg} \mathrm{P} \mathrm{ha}^{-1}+5 \mathrm{tlime} \mathrm{ha}^{-1}$ was as effective as the above two treatments in reducing exchangeable acidity and Al. Among sole treatments, application of $10 \mathrm{tlime}^{-1}$ reduced exchangeable acidity and Al significantly over the control (Table 5).

\section{Effects of organic and inorganic amendments on exchangeable bases}

Exchangeable Ca was significantly affected by organic and inorganic treatments and incubation period (Table 6). However, there was not statistically difference obtained as a result of organic and inorganic amendments on exchangeable $\mathrm{Mg}, \mathrm{K}$ and $\mathrm{Na}$ (Table 6 and 7). Highest exchangeable Ca was obtained at 20 days of incubation with the application of $30 \mathrm{~kg} \mathrm{P} \mathrm{ha}^{-1}+10 \mathrm{tlime} \mathrm{ha}^{-1}$ followed by $4 \mathrm{t} \mathrm{ha}^{-1} \mathrm{FYM}+15 \mathrm{~kg} \mathrm{P} \mathrm{ha}^{-1}$ $+10 \mathrm{t} \mathrm{lime} \mathrm{ha}^{-1}$. Among sole treatments, lime at the 20 days and FYM at the 60 days gave highest exchangeable Ca. Period of incubation did not show consistency for exchangeable Ca and Mg. In most 
treatments of only lime and combinations having lime, exchangeable $\mathrm{Ca}$ and $\mathrm{Mg}$ showed antagonistic relationships. For example, applications of $10 \mathrm{t}$ lime ha-1, $30 \mathrm{~kg} \mathrm{P} \mathrm{ha}^{-1}+10 \mathrm{tlime} \mathrm{ha}^{-1}, 8 \mathrm{t}$ compost ha-1 $+5 \mathrm{t}$ lime ha-1, 8 t FYM ha ${ }^{-1}+30 \mathrm{~kg} \mathrm{P} \mathrm{ha}^{-1}+5 \mathrm{t} \mathrm{ha}^{-1}$ lime ha-1 brought about a decrease in exchangeable Ca with an increase in exchangeable $\mathrm{Mg}$ with increasing incubation period.

Table 6. Effects of organic and inorganic amendments on exchangeable $\mathrm{Ca}$ and $\mathrm{Mg}$

\begin{tabular}{|c|c|c|c|c|c|c|}
\hline \multirow[t]{2}{*}{ Treatments } & 20 days & 40 days & 60 days & 20 days & 40 days & 60 days \\
\hline & \multicolumn{3}{|c|}{ Ex Ca $\left(\mathrm{cmol}_{\mathrm{c}} \mathrm{kg}^{-1}\right)$} & \multicolumn{3}{|c|}{$\operatorname{Ex~Mg}\left(\mathrm{cmol}_{\mathrm{c}} \mathrm{kg}^{-1}\right)$} \\
\hline Control & $9.98 \mathrm{~lm}$ & $10.43 \mathrm{~lm}$ & $11.11 \mathrm{i}-\mathrm{m}$ & 4.26 & 4.11 & 3.82 \\
\hline 8 t compost ha-1 & $10.82 \mathrm{j}-\mathrm{m}$ & $11.22 \mathrm{i}-\mathrm{m}$ & $13.16 \mathrm{f}-\mathrm{m}$ & 4.26 & 4.18 & 2.97 \\
\hline 8 t FYM ha ${ }^{-1}$ & $10.64 \mathrm{j}-\mathrm{m}$ & $10.48 \mathrm{klm}$ & $13.29 \mathrm{f}-\mathrm{l}$ & 4.87 & 5.29 & 3.21 \\
\hline 30 kg P ha-1 & $9.32 \mathrm{~m}$ & $11.11 \mathrm{i}-\mathrm{m}$ & $11.50 \mathrm{~h}-\mathrm{m}$ & 4.81 & 3.53 & 3.26 \\
\hline $10 \mathrm{t} \mathrm{lime} \mathrm{ha}^{-1}$ & $17.48 \mathrm{a}-\mathrm{e}$ & $17.06 a-f$ & $15.40 \mathrm{~b}-\mathrm{h}$ & 2.15 & 3.97 & 4.05 \\
\hline $30 \mathrm{~kg} \mathrm{P} \mathrm{ha}^{-1}+10 \mathrm{t} \mathrm{lime} \mathrm{ha}^{-1}$ & $19.54 a$ & 18.69abc & $14.11 \mathrm{~d}-\mathrm{k}$ & 2.68 & 4.24 & 4.58 \\
\hline $30 \mathrm{~kg} \mathrm{P} \mathrm{ha}^{-1}+5$ t lime ha-1 & $14.61 \mathrm{~d}-\mathrm{j}$ & $13.50 \mathrm{e}-\mathrm{l}$ & $14.56 \mathrm{~d}-\mathrm{j}$ & 2.66 & 4.87 & 3.81 \\
\hline 8 t compost ha- ${ }^{-1}+5$ t lime ha ${ }^{-1}$ & $15.83 a-g$ & $15.22 \mathrm{c}-\mathrm{h}$ & $14.32 \mathrm{~d}-\mathrm{k}$ & 2.73 & 3.84 & 4.00 \\
\hline 8 t FYM ha-1 +5 t lime ha ${ }^{-1}$ & $16.06 \mathrm{a}-\mathrm{g}$ & $15.01 \mathrm{c}-\mathrm{i}$ & $15.35 c-h$ & 2.50 & 4.13 & 3.18 \\
\hline 8 t compost ha ${ }^{-1}+30 \mathrm{~kg} \mathrm{P} \mathrm{ha}^{-1}+5 \mathrm{t}^{\mathrm{time} \mathrm{ha}} \mathrm{h}^{-1}$ & $15.06 \mathrm{c}-\mathrm{i}$ & $14.03 \mathrm{~d}-\mathrm{k}$ & $14.85 c-i$ & 3.29 & 3.55 & 3.55 \\
\hline 8 t FYM ha-1 $+30 \mathrm{~kg} \mathrm{P} \mathrm{ha}^{-1}+5$ t lime ha $^{-1}$ & $15.90 \mathrm{a}-\mathrm{g}$ & $14.48 \mathrm{~d}-\mathrm{j}$ & $14.22 \mathrm{~d}-\mathrm{k}$ & 2.39 & 5.23 & 6.50 \\
\hline $4 \mathrm{t}$ compost ha-1 $+15 \mathrm{~kg} \mathrm{P}^{-1}+10 \mathrm{t}^{-1}$ lime ha-1 & $17.53 \mathrm{a}-\mathrm{e}$ & $16.64 b-f$ & $16.22 b-f$ & 3.24 & 5.23 & 5.55 \\
\hline 4 t FYM ha-1 $+15 \mathrm{~kg} \mathrm{P} \mathrm{ha}^{-1}+10$ t lime ha-1 $^{-1}$ & $19.35 \mathrm{ab}$ & $17.85 a-d$ & 17.14a-f & 2.37 & 4.23 & 4.92 \\
\hline 4 t compost ha ${ }^{-1}+15 \mathrm{~kg} \mathrm{Pha}^{-1}+5 \mathrm{t} \mathrm{lime} \mathrm{ha}^{-1}$ & $15.58 b-g$ & $12.80 \mathrm{~g}-\mathrm{m}$ & $13.23 \mathrm{f}-\mathrm{l}$ & 2.21 & 3.25 & 3.55 \\
\hline 4 t FYM ha $^{-1}+15 \mathrm{~kg} \mathrm{P} \mathrm{ha}^{-1}+5 \mathrm{t} \mathrm{lime} \mathrm{ha}^{-1}$ & $16.15 a-f$ & $15.30 \mathrm{~d}-\mathrm{h}$ & $14.36 \mathrm{~d}-\mathrm{j}$ & 2.50 & 3.55 & 3.67 \\
\hline CV (\%) & \multicolumn{3}{|c|}{13.10} & \multicolumn{3}{|c|}{42.37} \\
\hline
\end{tabular}

Means within a column followed by the same letter are not significantly different at $\mathrm{P}>0.001$; $\mathrm{CV}=$ coefficient of variation

Table 7. Effects of organic and inorganic amendments on exchangeable $\mathrm{K}$ and $\mathrm{Na}$

\begin{tabular}{|c|c|c|c|c|c|c|}
\hline \multirow[t]{2}{*}{ Treatments } & 20 days & 40 days & 60 days & 20 days & 40 days & 60 days \\
\hline & \multicolumn{3}{|c|}{ Ex K $\left(\mathrm{cmol}_{\mathrm{c}} \mathrm{kg}^{-1}\right)$} & \multicolumn{3}{|c|}{$\mathrm{Ex} \mathrm{Na}\left(\mathrm{cmol}_{\mathrm{C}} \mathrm{kg}^{-1}\right)$} \\
\hline Control & 0.50 & 0.48 & 0.55 & 0.38 & 0.44 & 0.37 \\
\hline $8 \mathrm{t}$ compost ha ${ }^{-1}$ & 0.55 & 0.50 & 0.49 & 0.34 & 0.49 & 0.33 \\
\hline 8 t FYM ha-1 $^{-1}$ & 0.45 & 0.53 & 0.55 & 0.29 & 0.42 & 0.39 \\
\hline 30 kg P ha-1 & 0.47 & 0.53 & 0.54 & 0.29 & 0.37 & 0.39 \\
\hline $10 \mathrm{t}_{\text {lime }} \mathrm{ha}^{-1}$ & 0.47 & 0.54 & 0.49 & 0.30 & 0.45 & 0.36 \\
\hline $30 \mathrm{~kg} \mathrm{P} \mathrm{ha}^{-1}+10 \mathrm{t} \mathrm{lime} \mathrm{ha}^{-1}$ & 0.49 & 0.52 & 0.51 & 0.30 & 0.44 & 0.37 \\
\hline 30 kg P ha-1 +5 t lime ha-1 & 0.47 & 0.51 & 0.57 & 0.37 & 0.36 & 0.43 \\
\hline 8 t compost ha- ${ }^{-1}+5$ t lime ha ${ }^{-1}$ & 0.48 & 0.51 & 0.51 & 0.31 & 0.35 & 0.36 \\
\hline 8 t FYM ha-1 + 5 t lime ha-1 & 0.44 & 0.56 & 0.54 & 0.35 & 0.47 & 0.36 \\
\hline $8 \mathrm{t}$ compost ha ${ }^{-1}+30 \mathrm{~kg} \mathrm{Pha}^{-1}+5 \mathrm{t} \mathrm{lime} \mathrm{ha}^{-1}$ & 0.49 & 0.53 & 0.56 & 0.39 & 0.53 & 0.42 \\
\hline 8 t FYM ha-1 +30 kg P ha $^{-1}+5$ t lime ha-1 & 0.55 & 0.47 & 0.54 & 0.32 & 0.34 & 0.39 \\
\hline $4 \mathrm{t}$ compost ha-1 $+15 \mathrm{~kg} \mathrm{Pha}^{-1}+10 \mathrm{t} \mathrm{lime} \mathrm{ha}^{-1}$ & 0.53 & 0.53 & 0.54 & 0.32 & 0.39 & 0.38 \\
\hline 4 t FYM ha-1 + $15 \mathrm{~kg} \mathrm{P} \mathrm{ha}^{-1}+10$ t lime ha-1 & 0.49 & 0.50 & 0.53 & 0.30 & 0.41 & 0.36 \\
\hline 4 t compost ha-1 $+15 \mathrm{~kg} \mathrm{P} \mathrm{ha}^{-1}+5 \mathrm{t} \mathrm{lime} \mathrm{ha}^{-1}$ & 0.41 & 0.45 & 0.51 & 0.41 & 0.32 & 0.38 \\
\hline 4 t FYM ha ${ }^{-1}+15 \mathrm{~kg} \mathrm{P} \mathrm{ha}^{-1}+5 \mathrm{t} \mathrm{lime} \mathrm{ha}^{-1}$ & 0.55 & 0.52 & 0.54 & 0.35 & 0.33 & 0.36 \\
\hline $\mathrm{CV}(\%)$ & \multicolumn{3}{|c|}{11.05} & \multicolumn{3}{|c|}{18.32} \\
\hline
\end{tabular}

$\mathrm{CV}=$ coefficient of variation

\section{Effects of organic and inorganic amendments on ECEC and exchangeable cation ratios}

Effective cation exchange capacity was affected significantly due to organic and inorganic treatment applications (Table 8). Sole or combined applications of lime, compost and FYM improved the ECEC of the soil. Considering sole treatment applications compared with the control, addition of $10 \mathrm{t} \mathrm{lime} \mathrm{ha-1}$ elevated ECEC from the respective control to 21.08 and $22.30 \mathrm{cmol}_{\mathrm{c}} \mathrm{kg}^{-1}$ at the 20 and 40 days of incubation, respectively. Likewise, combined applications of $30 \mathrm{~kg} \mathrm{P} \mathrm{ha}^{-1}+10 \mathrm{t}$ lime ha-1, $4 \mathrm{t} \mathrm{FYM} \mathrm{ha}{ }^{-1}+15 \mathrm{~kg} \mathrm{P} \mathrm{ha}^{-1}+10 \mathrm{t}$

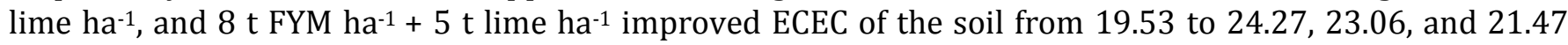
$\mathrm{cmol}_{\mathrm{C}} \mathrm{kg}^{-1}$, respectively at the 40 days of incubation.

The effects of separate or combined application of organic and inorganic amendments on the ratio of exchangeable $\mathrm{Ca} / \mathrm{K}$ was significant but it was found non-significant on the ratio of $\mathrm{Ca} / \mathrm{Mg}$ and $\mathrm{Mg} / \mathrm{K}$ (Table 8). However, it was observed that numerical variations exist among the treatments and the incubation periods. Application of $4 \mathrm{t} \mathrm{FYM} \mathrm{ha-1}+15 \mathrm{~kg} \mathrm{P} \mathrm{ha}^{-1}+10 \mathrm{tlime} \mathrm{ha}^{-1}$, and $10 \mathrm{tlime} \mathrm{ha-1}+30 \mathrm{~kg} \mathrm{P}^{-1} \mathrm{increased}^{-1}$ the ratio of $\mathrm{Ca} / \mathrm{K}$ from 19.98 to 40.75 and 40.54 , respectively at the 20 days of incubation. 


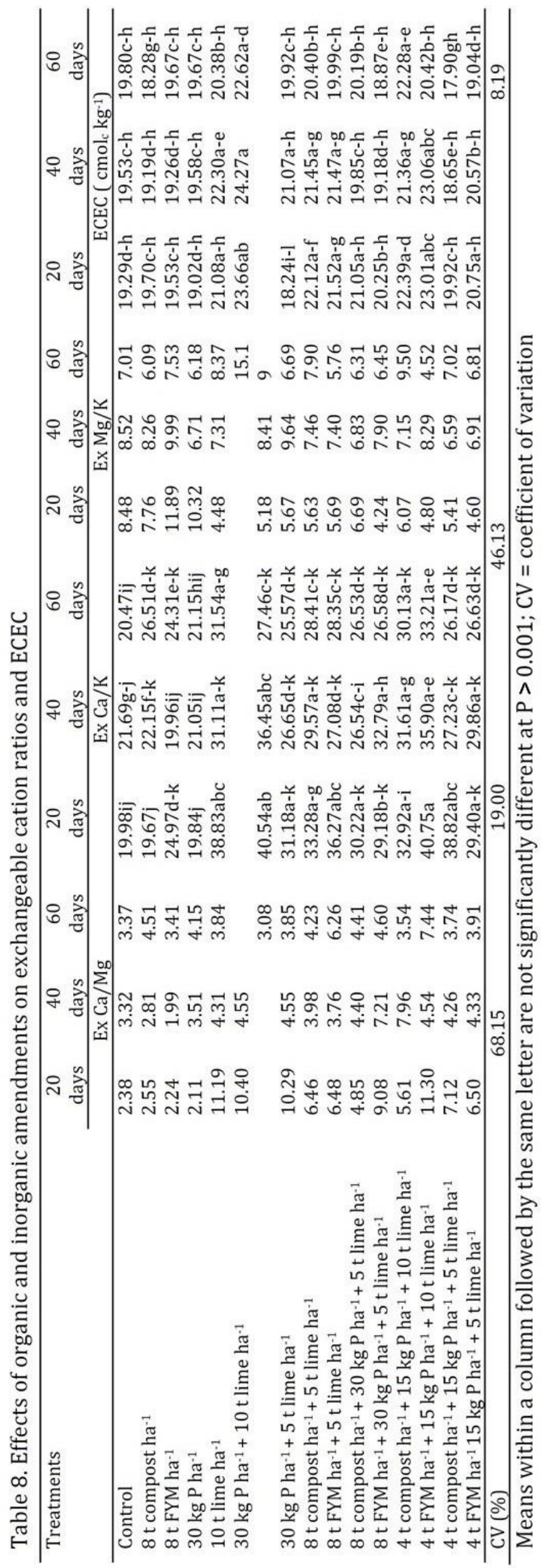




\section{Discussion}

The effect of FYM or compost when applied separately to increase the $\mathrm{pH}$ was less as compared to sole lime application. However, when $4 \mathrm{t} \mathrm{ha}^{-1}$ of either FYM or compost was applied with half rate of lime brought the soil pH to 5.97 and 5.75 , respectively at the 40 days of incubation which could be considered as the favorable $\mathrm{pH}$ range for crop production. Although increasing the lime rate from 5 to $10 \mathrm{t} \mathrm{ha}^{-1}$ in the combination showed a linear increase in soil pH, combined application of half FYM or compost with half lime and P could be sufficient to improve soil $\mathrm{pH}$ to a level where soil acidity is reduced and nutrient availability is increased. Unlike this finding of gradual pH change due to FYM or compost, Whalen et al. (2000) reported an immediate increase in the $\mathrm{pH}$ of acid soils after application of fresh cattle manure, and the effect persisted during 60 days of incubation of soil manure mixtures. The high initial $\mathrm{pH}$, exchangeable bases and proton consumption capacity may contribute to raise pH of FYM or compost amended soil. Ortiz Escobar and Hue (2008) indicated similar effects on soil $\mathrm{pH}$ after manure or compost applications. Another justification could be due to the buffering of carbonates and bicarbonate and other compounds, such as organic compounds with carboxyl and phenolic hydroxyl functional group, which consume proton and control the variation of $\mathrm{pH}$ in soils and their ability of buffering to neutralize soil acidity (Mokolobate and Haynes, 2002; Naramabuye and Hayes, 2007). In the case of lime, the increase in soil moisture causes the dissociation of the carbonates of Ca at the end of the reaction, the release of $\mathrm{OH}^{-}$ions in the solution, which increases soil pH (Verde et al., 2013; Moreira et al., 2015). The $\mathrm{pH}$ decline after 40 days of incubation was attributed to the $\mathrm{H}^{+}$produced during the conversion of organic $\mathrm{N}$ and $\mathrm{S}$ to $\mathrm{NO}_{3}{ }^{-}$and $\mathrm{SO}_{4}{ }^{2-}$, respectively. However, this acidification is an artefact of incubation in closed area favoring $\mathrm{NO}_{3}$ accumulation (Samake, 2014). But under field conditions much nitrate produced would be absorbed by growing plants leading to $\mathrm{OH}^{-}$releasing that can neutralize soil acidity (Heyar and Porter, 1989).

The increased availability of $\mathrm{P}$ with time due to application of FYM or compost separately or in the combination could be the result of gradual mineralization of OM (Opala et al., 2010) and the release of organic acids that bound with $\mathrm{Al}$ and decreased $\mathrm{P}$ fixation (von Wandruszka, 2006). Net P mineralization would also be expected to occur because FYM had a higher P concentration $(0.31 \%)$ than the critical level of $0.25 \%$ required for net $P$ mineralization (Nziguheba et al., 1998). The presence of humic acid and fulvic acid on soil and oxide surfaces restricted subsequent $P$ adsorption (Mokolobate and Haynes, 2002). The observed earlier availability of highest $\mathrm{P}$ with lime and $\mathrm{P}$ application might be due to the rapid neutralization of soil acidity and increased solubility of the applied TSP fertilizer. An increase in the available P content in strongly acidic soil after liming was also recorded in other experiments (Özenç and Özenç, 2009; Jaskulska et al., 2014). Generally, incubation of all various combinations for 60 days, and incubation of $30 \mathrm{~kg} \mathrm{P} \mathrm{ha}^{-1}$ plus $10 \mathrm{t}$ lime $\mathrm{ha}^{-1}$ for 20 days could improve the soil available $\mathrm{P}$ to the moderate range.

When full or half rate of FYM, or compost was combined with half or full rate of lime in the treatment combinations, exchangeable $\mathrm{Al}^{3+}$ was observed to the level of non toxicity at the 60 days of incubation, indicating that including organic amendments could reduce soil acidity but with a relatively slower rate. This may be ascribed to the time taken for complete decomposition of the applied OM. Although both lime and FYM contributed in reducing exchangeable acidity and $\mathrm{Al}$, the changes observed were largely attributed to the applied lime. Because it was shown that among separate treatment applications, lime was superior to reduce soil acidity. Application of lime tends to raise the soil $\mathrm{pH}$ and reduce acidity by displacement of $\mathrm{H}^{+}$, $\mathrm{Fe}^{2+}, \mathrm{Al}^{3+}$ and $\mathrm{Mn}^{4+}$ ions from soil adsorption site (Osundwa et al., 2013; The et al., 2006). Similarly, Fageria and Baligar (2008) explained the presence of cations such as $\mathrm{Ca}^{2+}$ in lime exchange and/or replace $\mathrm{H}^{+}$on the exchange sites and anions such as $\mathrm{CO}_{3}{ }^{2-}$ and $\mathrm{OH}^{-}$to neutralize the $\mathrm{H}^{+}$released from the exchange sites and hydrolyzing $\mathrm{Al}$ species to the soil solution. Liming of acidic soils increased soil $\mathrm{pH}$ and exchangeable bases thereby reducing the magnitude of soil acidity, exchangeable acidity and Al saturation (Osundwa et al., 2013).

Ano and Ubochi (2007) indicated that animal manures significantly increased the soil $\mathrm{pH}$ from 4.6 to values above 5.6 and also reduced exchangeable acidity from $3.00 \mathrm{cmol} \mathrm{kg}^{-1}$ to values below $0.35 \mathrm{cmol} \mathrm{kg}^{-1}$. Another study conducted in acidic soil in Kenya reported application of FYM increased the soil pH and reduced the exchangeable acidity and $\mathrm{Al}$ in the short term, but the inorganic P sources did not significantly affect these parameters (Opala et al., 2012). Many studies have indicated that addition of OM to acidic soils can reduce $\mathrm{Al}$ toxicity (Liasu et al., 2008; Melese and Yli-Halla, 2016). Organic matter reduces Al toxicity and its acidulating effects either by chelating or encapsulating the $\mathrm{Al}^{3+}$ (Obiri-Nyarko, 2012). An increase in soil $\mathrm{pH}$ due to manure application apparently results in precipitation of exchangeable and soluble $\mathrm{Al}$ as insoluble $\mathrm{Al}$ 
hydroxides thus reducing concentration of $\mathrm{Al}$ in soil solution (Ano and Ubochi, 2007; Melese and Yli-Halla, 2016).

Several researchers reported increased Ca and Mg as a result of lime (Fageria and Baligar, 2003) and FYM (Kheyrodin and Antoun, 2012; Verde et al., 2013) applications on acid soils. The increased Ca could be due to the dissociation of lime and the decomposition of OM (Fageria and Baligar, 2003). In agreement with this result, Rahman et al. (2002) also found increased available Ca in the soil as a result of applied manure either alone or combined with lime and attributed the increase to improved Ca availability as a result of improved soil $\mathrm{pH}$, as was observed in this study. The observed antagonistic relation between exchangeable $\mathrm{Ca}$ and $\mathrm{Mg}$ could be due to the rapid dissolution of $\mathrm{CaCO}_{3}$ to increase more exchangeable Ca that compete $\mathrm{Mg}$ to take the exchange site whereas the effect of decomposition of FYM or compost gradually improved the exchangeable $\mathrm{Mg}$ with increasing period of incubation from 20 to 60 days.

The elevation of ECEC is due to the effect of lime that increase the $\mathrm{Ca}^{2+}$ concentration in the exchange site. Moreover, the improvement could also be attributed to the integrated effect of the amendments by improving soil $\mathrm{pH}$, microbial activity, and exchangeable bases from FYM and compost decomposition. Increased ECEC and nutrient concentrations in acidic soils amended with compost or manure were observed in Senegal's peanut basin (McClintock and Diop, 2005). Other researchers (Ano and Ubochi, 2007; Naramabuye and Hayes, 2007) have reported significant increases in exchangeable $\mathrm{Ca}, \mathrm{Mg}$ and ECEC following the application of organic materials. In the same way, Fageria et al. (2014) reported liming acidic soil significantly increased base saturation and ECEC.

The observed increased ratio of $\mathrm{Ca} / \mathrm{K}$ was due to the availability of $\mathrm{Ca}$ from the applied lime rate. Although statistically, non significant values were obtained for $\mathrm{Ca} / \mathrm{Mg}$ and $\mathrm{Mg} / \mathrm{K}$ ratios, the nutrient balance is more affected by the magnitude of the ratio. The influence of liming on cation ratio has been reported (Fageria et al., 2014). Graham (1959) proposed that for production of annual crops, ratio ranges of 7.1 to 10.8 for $\mathrm{Ca} / \mathrm{Mg}, 17.0$ to 32.5 for $\mathrm{Ca} / \mathrm{K}$, and 2.4 to 3.0 for $\mathrm{Mg} / \mathrm{K}$ in soils are needed. Calculated values of $\mathrm{Ca} / \mathrm{Mg}$ ratio for the applied $30 \mathrm{Kg} \mathrm{P} \mathrm{ha}^{-1}+5$ or $10 \mathrm{t} \mathrm{lime} \mathrm{ha}^{-1}$ at the 20 days incubation, and $8 \mathrm{t} \mathrm{FYM} \mathrm{ha}^{-1}+15 \mathrm{~kg} \mathrm{Pha}^{-1}+5 \mathrm{t}$ lime ha-1 at the 40 days incubation showed in the proposed range. The ratio of $\mathrm{Ca} / \mathrm{K}$ in most of separate or combined treatments across the incubation period could be considered as the favorable ratio for most crops whereas the $\mathrm{Mg} / \mathrm{K}$ ratio obtained was higher than the proposed values. Kopittke and Menzies (2007) reviewed that examination of data from numerous studies would suggest that, within the ranges commonly found in soils, the chemical, physical, and biological fertility of a soil is generally not influenced by the ratios of $\mathrm{Ca}, \mathrm{Mg}$, and $\mathrm{K}$.

\section{Conclusion}

Application of lime, FYM and compost brought significant change in the selected soil chemical properties of acidic soil incubated at various periods. Application of $10 \mathrm{t}$ lime ha-1 alone or $5 \mathrm{t}$ lime ha-1 combined with $4 \mathrm{t}$ ha $^{-1}$ FYM or compost showed a marked increase in pH at the 20 and 40 days of incubation. All treatments showed increased $\mathrm{P}$ availability consistently with increasing time of incubation. Maximum available $\mathrm{P}$ was observed at the 60 days of incubation due to application of $8 \mathrm{t} \mathrm{ha}^{-1} \mathrm{FYM}+30 \mathrm{~kg} \mathrm{P} \mathrm{ha}^{-1}+5 \mathrm{t} \mathrm{lime} \mathrm{ha-1}$ followed by $8 \mathrm{t} \mathrm{ha}^{-1}$ compost $+30 \mathrm{~kg} \mathrm{P} \mathrm{ha}^{-1}+5 \mathrm{t} \mathrm{lime} \mathrm{ha-1}^{-1}$. Highest exchangeable Ca was obtained at 20 days of

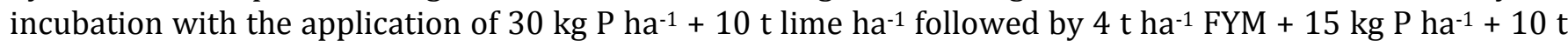
lime ha-1. Among sole treatments, lime at the 20 days and FYM at the 60 days gave highest exchangeable Ca. Maximum reduction of exchangeable acidity and Al were recorded with the application of $30 \mathrm{~kg} \mathrm{P} \mathrm{ha}^{-1}+10 \mathrm{t}$ lime ha-1 followed by $4 \mathrm{t}$ FYM or compost ha-1 $+15 \mathrm{~kg} \mathrm{P}^{-1}+10 \mathrm{t}$ lime ha-1 at the 40 and 60 days of incubation. Considering the incubation period, application of all treatments except sole $\mathrm{P}$ consistently reduced exchangeable acidity and $\mathrm{Al}$ with increasing time. More exchangeable acidity and $\mathrm{Al}$ were reduced at the 40 and 60 days of incubation with the combined application of FYM, P and lime. Application of $8 \mathrm{t}$ FYM

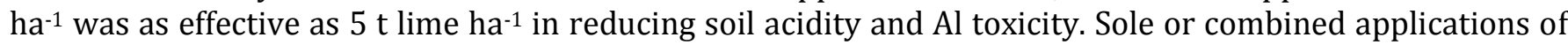
lime, compost and FYM improved the ECEC of the soil. Thus, combined application of $4 \mathrm{t} \mathrm{FYM} \mathrm{ha}^{-1}, 15 \mathrm{~kg}^{\mathrm{P}}$ ha$1+10 \mathrm{t}$ lime ha-1 or $8 \mathrm{t} \mathrm{FYM} \mathrm{ha}{ }^{-1}, 30 \mathrm{~kg} \mathrm{P} \mathrm{ha}^{-1}+5 \mathrm{tlime} \mathrm{ha}^{-1}$ could be taken as alternative strategy in the efforts of acidic soil management and improve soil nutrient status in Lay Gayint district.

Generally, it would be possible to increase the soil nutrient content and reduce the level of soil acidity with integrated application of organic and inorganic amendments but the time of application should be considered. For lime, FYM and compost combinations, 40 to 60 days of incubation earlier to planting would allow decomposition and chemical reaction with the soil. Since the experiment was done in the greenhouse for only one round, it should be repeated in the field for long years to obtain consistent results. 


\section{References}

Addisu, B., Menberu, T., 2015. Crop Sensitivity to inter-annual climate variability in Lay Gayint woreda, Northwest Ethiopia. Ethiopian Renaissance Journal of Social Sciences and the Humanities 2: 27-42.

Anjos, J.T., Rowell, D.L., 1987. The effect of lime on phosphorus adsorption and barley growth in three acid soils. Plant and Soil 103(1): 75-82.

Ano, A.O., Ubochi, C.I., 2007. Neutralization of soil acidity by animal manures: Mechanism of reaction. African Journal of Biotechnology 6(4): 364-368.

Baruah, T.C., Barthakur, H.P., 1997. A textbook of soil analyses. Vikas Publishing House Pvt. Ltd. New Delhi, India.

Chapman, H.D., 1965. Cation exchange capacity. In: Methods of Soil Analysis. Part II, Black, C.A. (Ed.). Agronomy No. 9. American Society of Agronomy, Madison, Wisconsin, USA. pp. 891-901.

Chen, J.H., Wu, J.T., Huang, W.T., 2001. Effects of compost on the availability of nitrogen and phosphorus in strongly acidic soils. Food and Fertilizer Technology Center Extension Bulletin Vol. 155.

Chiu, K.K., Ye, Z.H., Wong, M.H., 2006. Growth of Vetiveria zizanioides and Phragmities australis on $\mathrm{Pb} / \mathrm{Zn}$ and Cu mine tailings amended with manure compost and sewage sludge: a greenhouse study. Bioresource Technology 97(1): 158-170.

Crawford, T.W., Singh, J.U., Breman, H., 2008. Solving agricultural problems related to soil acidity in Central Africa's Great Lake Region. Catalyst Project Report. An International Center for Soil Fertility and Agricultural Development. Alabama, USA. 133p. Available at: [access date: 08.08.2017]: http://twc0etal.freeshell.org/tom/soil_acidity/pdfs/Crawford_et_al_Soil_Acidity_Control_Report.pdf.

Day, P.R., 1965. Particle fractionation and particle-size analysis. In: Methods of Soil Analysis. Part I, Black, C.A. (Ed.). Agronomy No. 9. American Society of Agronomy, Madison, Wisconsin, USA. pp. p. 545-566.

Ethiopian National Meteorological Service Agency (ENMSA), 2017. Lay Gayint Weather Station Rain Fall and Temperature Data. Bahir Dar, Ethiopia.

Fageria , N.K. Moreira, A., Moraes, L.A.C., Moraes, M.F., 2014. Influence of lime and gypsum on yield and yield components of soybean and changes in soil chemical properties. Communications in Soil Science and Plant Analysis 45(3): 271-283.

Fageria, N.K., Baligar, V.C., 2008. Ameliorating soil acidity of tropical Oxisols by liming for sustainable crop production. Advances in Agronomy 99: 345-399.

Fageria, N.K., Baligar,V.C., 2003. Fertility management of tropical acid soils for sustainable crop production. In: Handbook of Soil Acidity. Rengel, Z. (Ed.), Marcel Dekker, Inc., New York, USA. pp. 359-385.

Graham, E.R., 1959. An explanation of theory and methods of soil testing. Missouri Agricultural Experiment Station Bulletin 734, University of Missouri, Columbia, Missouri. USA. Available at: [access date: 08.08.2017]: https://mospace.umsystem.edu/xmlui/bitstream/handle/10355/54881/AESbulletin.pdf?sequence=1\&isAllowe $\mathrm{d}=\mathrm{y}$.

Jackson, M.L., 1967. Soil Chemical Analysis. Prentice Hall of India Pvt. Ltd., New Delhi. 498p.

Jaskulska, I., Jaskulski, D., Kobierski, M., 2014. Effect of liming on the change of some agrochemical soil properties in a long-term fertilization experiment. Plant Soil and Environment 60(4): 146-150.

John, B.P. Recommended Method of Manure Analysis. 2003. University of Wisconsin, Cooperative extension publishing. USA.

Kheyrodin, H., Antoun, H., 2011. Tillage and manure effect on soil physical and chemical properties and on carbon and nitrogen mineralization potentials. African Journal of Biotechnology 10(48): 9824-9830.

Kisinyo, P.O., Opala, P.A. Gudu, S.O. Othieno, C.O. Okalebo, J.R. Palapala, V., Otinga, A.N., 2014. Recent advances towards understanding Kenyan acid soils for improved crop production. African Journal of Agricultural Research 9(31): 2397-2408.

Kopittke, P.M., Menzies, N.W., 2007. A Review of the use of the basic cation saturation ratio and the "Ideal" Soil. Soil Science Society of America Journal 71(2): 259-265.

Liasu, M.O., Ogundare, A.O., Ologunde, M.O., 2008. Effect of soil supplementation with fortified tithonia mulch and directly applied inorganic fertilizer on growth and development of potted okra plants. American-Eurasian Journal of Sustainable Agriculture 2(3): 264-270.

Martínez-Blanco, J., Cristina, L., Christensen, T.H., Muñoz, P., Rieradevall, J., Møller, J., Antón, A., Boldrin, A., 2013. Compost benefits for agriculture evaluated by life cycle assessment. A review. Agronomy for Sustainable Development 33(4): 721-732.

McClintock, N. Diop, A.M., 2005. Soil fertility management and compost use in Senegal's peanut basin. International Journal of Agricultural Sustainability 3(2): 79-91.

Melese, A., Yli-Halla, M., 2016. Effects of applications of lime, wood ash, manure and mineral P fertilizer on the inorganic $P$ fractions and other selected soil chemical properties on acid soil of Farta District, northwestern highland of Ethiopia. African Journal of Agricultural Research 11(2): 87-99..

Mokolobate, M.S., Haynes, R.J., 2002. Comparative liming effect of four organic residues applied to an acid soil. Biology and Fertility of Soil 35(2): 79-85.

Moreira, A., Sfredo, G.J., Moraes, L.A.C., Fageria, N.K., 2015. Lime and cattle manure in soil fertility and soybean grain yield cultivated in tropical soil. Communications in Soil Science and Plant Analysis 46(9): 1157-1169. 
Murphy, J., Riley, J.P., 1962. A modified single solution method for the determination of phosphate in natural waters. Analytica Chemica Acta 27: 31-36.

Naramabuye, F.X., Haynes, R.J., 2007. The liming effect of five organic manures when incubated with an acid soil. Journal of Plant Nutrition and Soil Science 170(5): 615-622.

Nziguheba, G., Palm, C.A., Buresh, R.J., Smithson, P.C., 1998. Soil phosphorus fractions and adsorption as affected by organic and inorganic sources. Plant and Soil 198(2): 159-168.

Obiri-Nyarko, F., 2012. Ameliorating soil acidity in Ghana: A concise review of approaches. APRN Journal of Science and Technology 2: 143-15.

Okalebo, J.R., Gathua, K.W., Woomer, P.L., 2002. Laboratory methods of soil and plant analysis, $2^{\text {nd }}$ Edition. A working manual, Nairobi, Kenya.

Olsen, S.R., Watenabe, V.C., Dean, L.A., 1954. Estimate of available phosphorous in soil by extraction with sodium bicarbonate. USDA Circular. No. 939, USA.

Opala, P., Okalebo, J.R., Othieno, C.O., Kisinyo, P., 2010. Effect of organic and inorganic phosphorus sources on maize yields in an acid soil in western Kenya. Nutrient Cycling Agroecosystems 86(3): 317-329.

Opala, P.A., Okalebo, J.R., Othieno, C.O., 2012. Effects of organic and inorganic materials on soil acidity and phosphorus availability in a soil incubation study. International Scholarly Research Network Article ID 597216.

Ortiz Escobar, M.E., Hue, N.V., 2008. Temporal changes of selected chemical properties in three manure-Amended soils of Hawaii. Bioresource Technology 99(18): 8649-8654.

Osundwa, M.A., Okalebo, J.R., Ngetich, W.K., Ochuodho, J.O., Othieno, C.O., Langat, B. and Omenyo, V.S., 2013. Influence of agricultural lime on soil properties and wheat (Triticum aestivum L.) yield on acidic soils of Uasin Gishu County, Kenya. American Journal of Experimental Agriculture 3(4): 806-823.

Özenç, N., Özenç, D.B., 2009. Interaction between available phosphorus and lime treatments on extremely acid pH soils of hazelnut orchards. Acta Horticulturae 845: 379-386.

Rahman, M.A., Meisner, C.A., Duxbury, J.M., Lauren, J., Hossain, A.B.S., 2002. Yield response and change in soil nutrient availability by application of lime, fertilizer and micronutrients in an acidic soil in a rice-wheat cropping system. The 17th World Congress of Soil Science. $14^{\text {th }}-21^{\text {st }}$ August, 2002. Bangkok, Thailand.

Rowell, D., 1994. Soil Science: Methods and Applications. Longman Group UK Limited, UK. 350p

Samake, A., 2014. Use of locally available amendments to improve acid soil properties and maize yield in the savanna zone of Mali. PhD Thesis, Kwame Nkrumah University of Science and Technology, Kumasi.

Shoemaker, H.E., McLean, E.O., Pratt, P.F., 1961. Buffer methods for determining lime requirement of soils with appreciable amounts of extractable aluminum. Soil Science Society of America Journal 25(4): 274-277.

Tessema, G., Argaw, M., Adgo, E., 2012. Farmers soil management practices and their perceptions to soil acidity at Ankesha District of Awi Zone, Northwestern Ethiopia. Libyan Agriculture Research Center Journal International 3: 64-72.

The, C., Calba, H., Zonkeng, C., Ngonkeu, E.L.M., Adetimirin, V.O., Mafouasson, H.A., Meka, S.S., Horst, W.J., 2006. Responses of maize grain yield to changes in acid soil characteristics after soil amendments. Plant and Soil 284(1-2): 45-57.

Valarini, P.J, Curaqueo, G., Seguel, A., Manzano, K., Rubio, R., Cornejo, P., Borie, F., 2009. Effect of compost application on some properties of a volcanic soil from central South Chile. Chilean Journal of Agricultural Research 69(3): 416425.

Verde, B.S, Danga, B.O., Mugwe, J.N., 2013. Effects of manure, lime and mineral P fertilizer on soybean yields and soil fertility in a humic Nitisols in the Central Highlands of Kenya. International Journal of Agricultural Science Research 2(9): 283-291.

von Wandruszka, R., 2006. Phosphorus retention in calcareous soils and the effect of organic matter on its mobility. Geochemical Transactions 7:6.

Walkley, A., Black, C.A., 1934. An examination of Digestion method for determining soil organic matter and proposed modification of the chromic acid titration method. Soil Science 37(1): 29-38.

Wassie, H., Shiferaw, B., 2009. Mitigation of soil acidity and fertility decline challenges for sustainable livelihood improvement: research findings from southern region of Ethiopia and its policy implications. Awassa Agricultural Research Institute.

Whalen, J.K., Chang, C., Clayton, G.W., Carefoot, J.P., 2000. Cattle manure amendments can increase the pH of acid soils. Soil Science Society of America Journal 64(3): 962-966. 